\title{
Autoria no documentário: o "filme-ensaio" de Fernando Solanas
}

\author{
Denise Tavares'
}

\begin{abstract}
Resumo
Este artigo insere-se na discussão em torno das definições do que seja documentário e os possiveis - ou não - contornos do gênero, incluindo a configuração da autoria, a partir de "Memoria del Saque" de Fernando "Pino" Solanas, considerando que o documentário, mesmo observado como objeto de "representação", sustenta-se também pelo grau de adesão à "verdade" ou o "foi assim", tanto em relação ao tema, quanto aos personagens e/ou fatos históricos que apresenta.
\end{abstract}

Palavras-chaves: Documentário; Fernando Solanas; Argentina; Cinema documentário; Cinema latino-americano

\begin{abstract}
This article is inserted in the quarrel around the definitions of that is documentary and the possibles - or the not - contours of the sort, including the configuration of the authorship, from "Memoria del Saque" of Fernando "pino" Solanas, considering that the set of documents, even observed as object of "representation", is supported, also, for the degree of adhesion to the "truth" or it "it was thus" as much in relation to the subject, how much to the historical persons and/or facts that present.
\end{abstract}

Keywords: Documentary film, Fernando Solanas, Argentina, Latin America Cinema

\footnotetext{
1 Denise Tavares é doutoranda no PROLAM/USP (Programa de Integração LatinoAmericano da Universidade de São Paulo) na àrea de "Comunicação e Cultura". Jornalista, Mestre em Multimeios pelo IAVUnicamp (área: cinema), professora da PUC-Campinas e diretora da Faculdade de Jornalismo da mesma Universidade, a partir de 2006.
} 


\section{Introdução}

Não faltam rupturas à trajetória do documentário na história do cinema. Como não faltam tradições que permanecem como referências ao gênero. Entre estas, a dificuldade constante em classificar um filme enquanto documentário. Dificuldades ampliadas pelo trânsito, cada vez mais intenso, de recursos estilísticos do cinema de fiç̧ão nos filmes que se afirmam documentários. Por isto mesmo, para Noël Carroll, ficar preso às diferenças formais não permite distinção entre os filmes de ficção e os de não-ficção. E este seria um primeiro passo necessário para se chegar à compreensão do que é filme documentário a quem ele coloca como subgênero do gênero não-ficção e classifica como "cinema da asserção pressuposta" (Carroll, 2006). Tal conceituação tem como um dos pontos de partida a intenção de comunicação do autor, isto é, sua pretensão de uma resposta específica do público que já recebe sua obra como documentário. A legitimação deste pressuposto se fundamenta na aplicação do modelo comunicativo de intenção-resposta, inspirado particularmente em Paul Grice. Aplicado, portanto, à relação cineasta-público, o modelo credita ao reconhecimento de boa parte do público das intenções de classificação do cineasta e a estas adere, antes mesmo de ir ao encontro da obra. Acrescente-se, ainda, a esta situação, conforme Carroll, todos os procedimentos presentes na atual organização social que colaboram para selar como "documentário" um filme que se apresente enquanto tal, independentemente, inclusive, dos recursos estilísticos que adota, desde que crie algumas "pontes" significativas com os cânones do gênero.

É claro que Carroll não deixaria de localizar os problemas epistemoló-gicos que sua argumentação pode provocar. Mas não se trata aqui de participar intensivamente deste debate que tem, entre outras companhias, Bill Nichols e Fernão Ramos, entre tantos outros que têm se debruçado sobre este cinema "do real". O primeiro localiza no percurso histórico do gênero as transformações decorrentes deste mesmo percurso, como ocorreu e ocorre na ficção:

"Vale a pena insistir no fato de que as estratégias e os estilos utilizados no documentário, assim como os do filme narrativo, mudam. Eles têm uma história. E mudam em grande parte pelas mesmas razões: os modos dominantes do discurso expositivo 
mudam, assim como a arena do debate ideológico". (Nichols, 2006: 47).

Nichols é hoje uma das referências para as pesquisas sobre documentário e autor da classificação de modelos para o gênero provavelmente os mais aceitas pelos os que se debruçam sobre a gênese desta produção. Mas é em torno da questão ética do documentário, construída ao longo da sua história e configurada a partir de procedimentos de realização, incluindo os estilísticos, que se classifica hoje o que Fernão Ramos chama de "três grandes constelações, ou sistemas" relacionados ao campo do documentário (Ramos, 2006: 168), que são: a tradição "clássica" - associada à escola documentarista inglesa tendo como grande referência John Grierson com um discurso assumidamente educativo e que reconhece no gênero uma função social positiva posição abraçada, no Brasil, por Humberto Mauro e Roquete Pinto à frente do INCE (Instituto Nacional do Cinema Educativo); a do "cinema-direto" - que girou em torno dos cineastas americanos Richard Leacock, D.A.Pennebaker e David Maysles e propunha a invisibilidade máxima possivel da câmera e, finalmente, a "participativoreflexivo" ou que incorporou a entrevista e a revelação do processo de realização do filme como um necessário desvendamento em relação às circunstâncias de realização do documentário e cujo marco é "Chronique d'un été", de Edgard Morin e Jean Rouch, de 1961.

Para além destas referências temos ainda a análise de Silvio Da-Rin, desenvolvida como dissertação de mestrado e posteriormente publicada (Da-Rin, 2004). Obra-painel, também recupera a travessia da construção do gênero até o que delimita como marcos de rupturas das tradições construidas ao longo da história do documentário, destacando a formulação de Nichols de auto-reflexividade, em que o aspecto principal do filme não é "o mundo representado, mas o próprio modo de representação" (Da-Rin, op. cit: 170). Nesta proposta, o autor localiza no Brasil a obra de Arthur Omar que radicalizaria ou mesmo desvendaria já uma "crise auto-reflexiva da representação" como fazem também os curtas de Jorge Furtado ("Iha das Flores", de 1989; "Esta não é sua vida", de 1990 e "A Matadeira", de 1994) e, por último, "Cabra Marcado para morrer", de Eduardo Coutinho, cncluido em 1984, dezessete anos a pós o início das filmagens, por conta do Golpe Militar no Brasil, de 1964. Para apontar esta crise Da-Rin debruça-se 
sobre os recursos estilísticos variados utilizados nestes filmes que "não demonstram o menor apreço pelas convenções do gênero. Se as utilizam, é para melhor criticá-las" (Da-Rin, op. cit: 215).

Mas não se trata aqui de se tentar exaurir todas as discussões e propostas sobre o que, afinal, configuraria o gênero ou, até mesmo, se tal é possível. Trata-se de delinear, mesmo que superficialmente, a abrangência deste percurso para que possamos tentar localizar, ao nos centrarmos especialmente sobre "Memoria del saque", do diretor argentino Fernando Solanas, um processo criativo que configura um estilo o que, por sua vez, torna-o coerente ao conceito do documentário como "filme de asserção pressuposta" e também permite sua inclusão na discussão sobre "voz documentária" que Nichols propõe - a que reconhece no estilo híbrido uma série de virtudes, entre elas "a clara consciência de que se está produzindo determinado significado por meio de determinada intervenção". (Nichols, 2006: 66).

\section{A construção de um estilo}

Em 2004, Fernando Solanas recebe o Urso de Ouro oferecido pelo Festival de Berlim pelo conjunto da obra. O prêmio coroa uma trajetória iniciada com um curta-metragem - "Seguir andando" realizado em 1962. Foi a porta de entrada de Solanas para o universo cinematográfico: "O filme, de uns vinte minutos, tem certa sensibilidade e foi importante principalmente porque me permitiu compreender que poderia me dedicar à direção". (Labaki e Cereghino, 1993: 25). A formação do cineasta inclui um estreito vínculo com a música (chegou a considerar a hipótese de ser pianista profissional), com o teatro e com a publicidade. Ainda, a participação ativa nos círculos políticos e culturais da Argentina que nos anos 60 reverenciavam, como boa parte da esquerda na América Latina, a revolução cubana. (Não podemos esquecer que o "Che" é argentino...). Neste contexto, uma questão, segundo Solanas, norteava seus planos para a produção de filmes:

"Em 1963 comecei a juntar toda a espécie de material filmado (noticiários e documentários) relacionado com a história recente da Argentina. Já planejava realizar um grande filme sobre meu País. Minha preocupação primordial concentrava-se no tema da 
identidade: quem somos? O que está acontecendo?" (Labaki\&Cereghino, op.cit. : 27).

O caminho para encontrar as respostas a estas questões, naquele periodo, passou, para Solanas, pelos documentários brasileiros e cubanos que chegavam à Argentina e também pelo Cinema Novo brasileiro, em especial pela obra e pessoa de Glauber Rocha. O diretor também cita "Maioria Absoluta" de Leon Hirszman como inquestionável influência ao grupo de jovens cineastas do qual fazia parte. Outras referências foram o cinema de Eisenstein e de Pudovkin, os documentários de Joris Ivens, os primeiros longas de Pasolini e o clássico "A Batalha de Argel", de Gillo Pontecorvo. (Labaki e Cereghino, op.cit.: 31). E, sempre, pela vontade de criar uma obra conectada aos ideais revolucionários daquele tempo, acentuados mais tarde pelo Manifesto do Che, de 1967, escrito na Bolivia, que pregava com urgência a idéia de "el hombre nuevo". Estas foram as bases para que Fernando Solanas e Octavio Getino construíssem "La hora de los hornos" que tem "como ponto de partida realizar uma obra sobre a realidade argentina das décadas de 40,50 e 60" (Labaki e Cereghino, op.cit.: 34).

Concebido deste modo, fruto de um propósito - realizar uma "crônica histórica" que fosse recebida como obra mobilizadora do público -, está em "La hora de los hornos" uma série de opções estilísticas que se reafirmam em outros filmes de Solanas, incluindo os ficcionais. Tendo como escola a produção publicitária, o diretor argentino credita à necessidade de síntese e o rigor dos enquadramentos, necessários aos filmes publicitários, muito das opções que adotou ao longo da sua carreira e fortemente presentes em "La hora de los hornos". Também nele estão os grafismos, o uso de legendas, a pontuação e o ritmo dados pela música, a pesquisa histórica, o resgate de cinejornais e, principalmente, a superação do gênero.

"La hora de los hornos" tornou-se um marco para o documentário latino-americano por muitos motivos. Concluído dez meses após a morte de Ernesto Che Guevara, na Itália, o filme foi apresentado durante o Festival de Pesaro, em junho de 1968, e provocou fortes comoções no público, principalmente por apresentar a face do guerrilheiro argentino morto, em imagem conquistada de um cinejornal que teve circulação restrita, mesmo em território latino-americano. Dividido em três partes 
- a primeira concentra as maiores denúncias enquanto a segunda e a terceira parte acumulam dados históricos sobre as décadas de 40 e 50 - o filme perambulou no circuito alternativo de vários países, inclusive o Brasil. A música foi composta por Solanas que investiu em progressões rítmicas e não se negou a ousadias que, com certeza, poucos (incluindo músicos profissionais) arriscariam.

Como se sabe, o continente chegou aos anos 1970 já atravessado pela atuação intensa dos EUA que não só combateu vigorosamente os governos democráticos da América Latina, como interferiu ativamente para que as novas ditaduras ganhassem fôlego e atuassem repressivamente contra quaisquer iniciativas populares que visassem a restauração da democracia. $\mathrm{Na}$ Argentina os militares assumem em 1976 e em junho deste ano Fernando Solanas é obrigado a partir do seu país exilando-se, a partir de 1977, na França, depois de ter tentado instalar-se na Venezuela, no México, na Itália e Espanha. Levava na bagagem a rica experiência do grupo "Cine Liberación", iniciado durante as filmagens de "La hora de los hornos", que abrigou um grupo de jovens cineastas dispostos a construir uma filmografia que 80 considerava a urgência de uma "terceira via" de produção, distinta dos modelos norte-americanos e europeus e profundamente comprometida com uma atuação política que significasse maior igualdade social. $\mathrm{O}$ grupo, que se separou em 1976, conseguiu realizar documentários e também o interessante "El camino hacia la muerte del viejo Reales" (O caminho rumo à morte do velho Reales), de Gerardo Vallejo, que já fundia, estilisticamente, a ficção e o documentário. Também é fruto do "Cine Liberación", a complicada produção "Los hijos de Fierro", projeto acalentado por Solanas mas que acumulou problemas de realização, incluindo o assassinato do ator Julio Troxler, em 1974, quando já havia começado os seqüestros e assassinatos na Argentina.

\section{Memórias do saque: retomada}

A volta à Argentina significou para Fernando Solanas, além da continuidade de sua carreira de cineasta ${ }^{2}$ o engajamento radical na luta contra a política e os políticos de seu país. Particularmente, ao que considerou "traição" do recém-eleito peronista Carlos Menen. Isso o levou à atuação direta também como político - foi candidato a senador e, posteriormente, eleito deputado - e figura atuante na construção de 
estratégias que impedissem o desmonte do pais e, também, mudanças na legislação do audiovisual, do teatro e da música. Suas denúncias repercutem dentro e fora da Argentina e em março de 1991, após acusar mais uma vez Carlos Menen de estar liderando um processo de saqueamento do patrimônio público em nome de uma política de redução do Estado (política presente em vários países da América Latina, inclusive Brasil), Fernando Solanas sofre um atentado, recebendo seis tiros que interromperam a produção de "El Viaje", filme que só conseguirá concluir no ano seguinte.

A marca deste episódio, evidente, norteia a continuidade da atuação do diretor argentino e no ano seguinte este encabeça a "Frente del Sur" que reuniu diversas partidos políticos e organizações sociais. Em seguida, 1993, participa da "Frente Grande", já como deputado, exercendo mandato até 1997 , quando retoma sua profissão de cineasta sem deixar de dar continuidade à militância política, em especial denunciando o desmonte estatal. Este acompanhamento visceral das políticas econômicas e sociais desenvolvidas seguidamente pelos presidentes que sucederam a ditadura militar na Argentina pode ser conferido em "Memoria del saque", rico em informações que só um profundo engajamento permitiria, por melhor que tenham sido as pesquisas em arquivos e cinejornais realizadas na fase de pré-produção do filme.

As primeiras imagens do filme, que poderíamos classificar de "apresentação" da obra, embaralham as ruas de Buenos Aires e crianças. Sentadas no chão ou fazendo gestos para a câmera em primeiro plano, remetem, principalmente pela câmera lenta e a trilha, às imagens-clichês que marcam os filmes-denúncias da miséria do terceiro mundo. Corte e a dedicatória do diretor: "Àqueles que resistiram todos esses anos. À sua dignidade e coragem". Em seguida, novo texto na tela - em uma estratégia também cara ao documentário dos anos 60 e 70 -, afixa as informações necessárias à compreensão da obra: "Argentina, outubro de 2001. O governo de Aliança é derrota nas eleições legislativas. $O$ presidente De la Rúa nega-se a mudar sua política. Em 2 anos de poder suas promessas de centro-esquerda foram substituidas..."

Após esta seqüência que contextualiza o filme e sua abordagem, Fernando Solanas introduz a estrutura da narrativa, concebida como um livro em capitulos, o que coloca "Memoria del saque" na mesma linha que conformou "La hora del hornos" e não se furta a recorrer a 
uma "voz/escrita" fora de campo, apresentando seqüências de frasessínteses (e, por isso mesmo, genéricas) animadas, de como vê a Argentina, de como acha que deva ser a Argentina, sobre a política governamental vigente no país e outras informações - assemelham-se a títulos de textos de jornais apresentados sobre fundo preto - que dialogam com tomadas de manifestações populares e também com trechos de telejornais, o último apresentando o presidente De La Rúa, quando este, em cadeia nacional, decreta o estado de sítio como resposta à movimentação das pessoas que tomaram as ruas centrais de Buenos Aires, dando forma a um grande protesto marcado pelo som do "panelaço" que, aos poucos, sobrepõe, primeiro, a voz do presidente e, logo, também a imagem.

$\mathrm{Na}$ nova seqüência, finalmente, temos a presença do diretor através da tomada. Se até agora todas as imagens se articulam para conformar um contexto e um clima e também para permitir o mergulho no passado, os travellings acelerados revelando a participação popular e os gritos das pessoas na rua repetindo "O povo, unido, jamais será vencido" e "Argentina, Argentina" permitem que o passado ganhe força, que o registro histórico surja e o filme passa, finalmente, a apresentarse, sem nenhuma dúvida, como documentário. Logo conseguiremos entender porque estas imagens parecem tão próximas e tão "verdadeiras", esgueirando-se da análise e interpretação facilmente coladas ao diretor: misturado aos acontecimentos é Fernando Solanas quem faz os registros, quem colhe depoimentos, quem atua como "repórter", incorporando a abordagem típica do jornalismo.

Esta estratégia continua no que poderia ser chamado de a "introdução" do filme. Assumindo o papel de narrador (ele não era a opção inicial, mas depois foi convencido pela equipe que ninguém narraria melhor do que ele todo o filme) o diretor reforça e explica os acontecimentos ali observados, ouvidos (há, também, depoimento de populares) até esta sequiência ser encerrada pela frase-tese que mobilizou a produção de "Memoria del saque": o que havia acontecido à Argentina? Como era possível que numa terra tão rica houvesse fome? - pergunta Solanas, dividindo com o público a motivação da obra e já deixando claro sua intenção de, como um cineasta militante (e investigador), encontrar uma ou mais respostas que irá apresentar, didaticamente, assentadas em duas câmeras distintas que confirmam um processo de criação que o embate com a "realidade" não irá alterar: 
o uso da grande angular - a que percorrerá os amplos espaços do poder oficial, em travellings vertiginosos, que fluem rápidos sob a voz do narrador que organiza as informações e significados que devem ser colados a estas imagens e outra "câmera" (muitas vezes trabalhando em parceria com sua mini-DV) - que acompanhará a movimentação do cineasta, muitas vezes presente no centro dos acontecimentos como testemunha, outras vezes investigando "in loco" as conseqüências da devastação que apresenta.

Como as ações populares e a situação atual da Argentina é resultado, para Solanas, de uma constante política de "depenação" do país, a lógica temporal é linear, demarcada e progressiva, o que cria registros estanques dos momentos históricos abordados. Para tentar ampliar esta circunferência o cineasta inclui imagens de arquivos de telejornais de várias partes do mundo, em trabalho que credita à memória do espectador a competência de articular estas informações. O cineasta também continua realizando o diálogo interno com a reaçào popular de 2001, justificando-a historicamente quando localiza sua raiz nas politicas entreguistas que resultaram en um estrondoso crescimento da dívida interna (tema do capítulo 1 do filme) escancarado, cinicamente, em outras imagens de arquivo que apresentam um debate onde o alto escalão governamental garante que é bom endividar-se.

O capítulo seguinte, denominado "Crônica da Traição", salta para 1983 e atravessa esta década, apresentando o presidente Alfonsín em defesa da "economia de guerra" que empreendeu como única saída para salvar a Argentina. A estratégia narrativa é a mesma, com recorrências às imagens de arquivo privilegiando os contrapontos e contradições entre a ação do governo e a resposta popular que já neste periodo mobilizava-se com ações que iam do protesto nas praças aos saques nos supermercados. Quanto ao foco na atuação do governo, este apresenta a renúncia de Alfonsín seis meses antes de terminar o mandato, a eleição de Menen e sua rápida mudança de posição, o que justifica o título deste "capitulo". Mais uma vez a música é a grande marca do estilo Solanas: é sob um tango que a traição é apresentada. E, para fechar esta seqüência já tão híbrida quanto aos modos de enunciação, o cineasta novamente assume sua porção de entrevistador com um senador justicialista que afirma ser a traição intrínseca à política. 
Nos capítulos seguintes - são 11 ao todo - Fernando Solanas mantém os mesmos recursos narrativos incorporando, ainda, grafismos, que distanciam, ainda mais o tom realista das entrevistas das interpretações apresentadas pelo cineasta. Há aqui um registro essencial no filme de Solanas que difere, fundamentalmente, dos documentários realizados sob a batuta jornalística cujo cerne é a necessidade de, ao recorrer ao singular, colar neste a generalização. Em um movimento contrário, o cineasta argentino, apesar de também recorrer ao singular, por sua postura militante e discurso coerente à ação, não se furta a dar nomes, a apontar políticas, a localizar os confrontos e perdas. À leitura desencarnada e com tão poucos nomes dos telejornais, ele contrapõe indicadores objetivos, incluindo os próprios telejornais, recuperando muitas frases e posturas que na tela pequena podem até ter passado despercebidas ou serem saudadas como as únicas possíveis já que embaladas pelo tom laudatório - registro típico das televisões abertas em boa parte dos países da América Latina, sob pretexto da objetividade e/ou neutralidade jornalística.

Neste momento gostaria de ressaltar algo que nem sempre é 84 observado em relação às definições que cercam as análises dos documentários na nossa contínua busca de colocarmos cercas claras. Como este percurso debruçou-se largamente sobre a enunciação, com bem destacou Fernão Ramos, (Ramos, op.cit), este procurou no resgate das condições em que se dá a "tomada" a caracterização da narrativa documentária. Para ele, é preciso que o esforço teórico sobre este gênero concentre-se, também, na dimensão da tomada sem que tal signifique deixar de lado a montagem/mixagem. Afinal, como Ramos referencia, na tradição clássica a inclusão da trilha, da voz-fora-de-campo, de falas e ruídos, têm estatuto semelhante ao que se encontra nos filmes ficcionais.

Fernando Solanas, com certeza, recorre à tradição clássica apesar de não a ela se prender em "Memoria del saque". O vigor da sua criação é resultante de um percurso que não negou sua presença no centro dos acontecimentos sobre os quais se debruça e também não negou uma opção estilística construída ao longo da sua carreira tais como os amplos travellings nos imensos espaços vazios ou ocupados por personagens que, distorcidos, acentuam o tom fantasmagórico do edifício, como acontece quando sua câmera adentra o Banco Nacional e, ainda, a pontuação da música orquestrada, marcando o ritmo da edição, criando 
o tom emocional para as imagens: "Meus trabalhos nascem como sinfonias corais, com verdadeiros leit motiv que se repeten ciclicamente" ((Labaki e Cereghino, op.cit.: 73). As tomadas do alto, também, nestes amplos espaços, confirmam os registros do diretor: a grande angular se aproxima muito veloz de quadros, paredes, esculturas áridas e bustos francamente identificados como dos "traidores da nação" e carrega o olhar do espectador para dentro dos símbolos de um sistema que expulsou drasticamente as camadas médias e populares da vida produtiva do pais.

A esta eixo de gravação contrapõe-se a vivacidade das ruas, as tomadas realizadas sob o calor das manifestações, colhidas em som direto, apresentando a "briga" para se alcançar o microfone do cineasta que, vez ou outra, se apresenta segurando sua mini-DV. Testemunha da história, referendado por sua biografia e filmografia, Fernando Solanas instaura seu enunciado garantindo-lhe o grau de "realidade" a que se pressupõe o documentário, principalmente por sua presença. A partir desta constatação poderemos ou não concordar com sua leitura, mas não conseguiremos negar o que ocorreu sob nossos olhos e pois lá estavam também, os do cineasta. É a "cicatriz da tomada", como coloca Ramos (op.cit.) aqui inegavelmente colada à presença do diretor - há um autor que se debruçou sobre a "realidade" e que foi possivel conhecer graças à mediação sujeito-câmera.

É, portanto, a partir desta trajetória militante que não exclui reflexão e opções balizadas pelo posicionamento claro quanto ao que é e como se faz cinema, que podemos localizar a obra de Solanas e, nesta, "Memoria del saque". Sei que as questões em torno da autoria emergem com vigor a partir da primeira metade dos anos 50, através da revista francesa "Cahiers du Cinéma", que lançou "uma proposta de crítica cinematográfica conhecida como a politica dos autores, que se tornaria célebre" (Bernardet, 1994: 9). Como o ensaio de Jean-Claude Bernardet discute, esta foi uma proposta que se espalhou mundo afora, incluindo o Brasil, e trouxe à tona a dificuldade de se garantir um conceito sólido devido, entre outros, aos múltiplos aspectos que a arte e o cinema em especial - por seu processo industrializado - colocam em torno do papel ativo (e único) do sujeito, na produção do "texto". Papel questionado pelos caminhos que garantem consistência ao conceito de autor, tais como unidade, produção de significados, 
configuração de um "estilo", a anterioridade da obra em relação ao sujeito que a concebe.

Mas, apesar de reconhecer a legitimidade do que traz Bernardet que inclui, inclusive, a participação de Fernando Solanas no que considera declínio do conceito (tratarei adiante deste tema), abro aqui um espaço para que "Memórias do saque" se apresente em uma leitura que destacará as articulações com a trajetória do cineasta, apesar de resgatada muito brevemente aqui, de modo que também possamos abrir a possibilidade de re-afirmar ao conceito de "documentário" sua definitiva autoria ampliando, deste modo, um possível paradoxo que se desmancha para logo se compor justamente porque o espectador comum, grosso modo, busca, inclusive na ficção, os indícios de que o mundo apresentado no espaço diegético seja possível fora dele. Ao ponto, tantas vezes, de um trecho de trilha ou um fragmento de imagem serem pontes objetivas à própria história de cada um, compactuando com a memória afetiva ou compreensão de fatos experenciados no cotidiano anônimo.

\section{Conclusão}

A discussão em torno do cinema autoral tem em Jean-Claude Bernardet e o seu "Autor no Cinema", uma minuciosa e densa contribuição. Nesta obra, Bernardet resgata o fio da autoria no cinema a partir da proposta definida pela revista francesa "Cahiers du Cinéma" na primeira metade dos anos 50, que ficou conhecida como "política dos autores". (Bernardet, op.cit.). E também apresenta o que considera o seu "declínio", incluindo como parceiro desta nova situação o manifesto de Octavio Getino e Fernando Solanas, publicado em 1969 - "Hacia um Tercer Cine" -, que teve intensa repercussão, segundo o mesmo Bernardet, na França, país-berço do conceito de cinema de autor, também pelo impacto significativo que provocou em vários países da Europa o documentário da mesma dupla, "La hora de los hornos".

Não se pretende, claro, resumir aqui a discussão que Bernardet faz em torno da política de autor e dos conceitos, nem sempre exclusivos, que a sustentaram. Quando se fala agora em autoria, e mesmo se recorre à coerência de tratamento criativo como um indicador significativo a ser observado na obra de um cineasta independente do gênero que cada um dos filmes realizados deste realizador explicita, a proposta é 
recuperar, também para o documentário, a importância do cineasta e seu papel nesta obra que, em tese, se constrói a partir de uma realidade dada. Ou seja, mesmo que assumamos o que parece ser hoje um conceito "pacificador" em relação à antiga (agora) discussão em torno de "o que é um documentário", reconhecendo-o tanto como "representação", "enunciação" ou "cinema de asserção pressuposta", sobram interrogações que, aparentemente, estão concentradas na "tomada" e na "enunciação" decorrente da montagem e/ou edição.

Por outro lado, não deixa de ser tentador vislumbrar o caminho apontado por Bernardet construído pelo diálogo que os teóricos do cinema e da arte travaram, em especial com Lacan e Barthes, provocando um deslocamento do autor que remete ao espectador. Segundo Jean-Claude, tal situação é ainda um "jogo de apostas que recusa uma escolha, resulta uma indecisão" (Bernardet, op.cit: 183), provocada, justamente, pelos "furos" que o conceito de autor carrega. De todo modo, quando se observa o contexto de produção de um filme como "Memoria del saque", parte primeira de um quarteto de filmes que tem como propósito configurar-se como uma "resposta" ou um caminho para se compreender a história recente da Argentina", tal deslocamento não deixa de provocar uma certa inquietação: afinal, qual a consistência da chamada "onda democrática" que, aparentemente, está presente na América Latina atual, configurada a partir de líderes eleitos sob o signo de "populares", como foi Lula, Morales e Chaves? Ou, em que lugar conseguir-se-á localizar o discurso/texto de Fernando Solanas, quando as utopias, as possibilidades do "nacional" se manter diante de uma economia globalizada ou a reconstrução econômica, social e política de um país como a Argentina não se apresentam enquanto projetos que conseguem se desvincular de toda a crise e questionamento que dilacerou o pensamento e a ação da esquerda em todo o mundo?

Há, na perspectiva dos que se debruçam sobre a produção cinematográfica, pelo menos duas grandes veredas em relação a como compreender ou refletir sobre filmes. Uma, que observa as obras a partir do que depreendem, enfatizando um processo de análise minucioso, plano a plano tantas vezes. Outra, que considera que o percurso citado anteriormente já foi suficiente para se criar um arcabouço teórico que precisa ser superado para que não corramos o risco de continuar, exaustivamente, olhando obra a obra para, ao final, 
chegarmos no mesmo ponto de partida. Não me atrevo a excluir um ou outro caminho. Ao contrário, apesar de aparentemente se negarem, vejo duas grandes matrizes que têm contribuído para que esta ainda incipiente política de produção e distribuição cinematográfica do continente latino-americano possa, quem sabe, ser superada em que pese esta afirmação já deixar de prontidão a antiga questão: há, realmente, um cinema latino-americano?

Esta é uma questão aberta, ainda. De qualquer modo, localizo na tradição militante do cinema latino-americano um testemunho de produção que rendeu fartas reflexões sobre nossa identidade, nossas desigualdades sociais, nossos compromissos com a memória, história. Do ponto de vista teórico, é um material que se coloca, apresentandose, no mínimo, como obra que permite múltiplas leituras, discussões. Afinal, para que existem as artes, os objetos da cultura?

Não podemos esquecer que, se hoje Solanas apresenta-se como "artista" esta afirmação não seria tão simples naquele final da década de 60. Pautados pelo conceito de nacionalismo definidos especialmente por Franz Fanon que o emparelhava à ação popular, cineastas como 88 Solanas e Getino mais do que autores definiam-se como ativistas, mesmo que as opções da autoria estivessem rasgadamente presentes na construção das suas obras, na gênese mesma das concepções: "Quis fazer um filme de amor. Alguns dizem que ele é muito político. Também não deixa de ser, porque todos os filmes são políticos", afirma o diretor em relação a "Sur".

O fato é que a força das conceituações e discussões se mantém, produzindo novos olhares e um esforço acentuado de construção teórica em torno do documentário enquanto os cineastas continuam suas produções multiplicando os espaços para as necessárias reflexões e análises que tais demandam, objetos da cultura e arte que são. Mas, de todo modo, é inegável que neste processo de valorização do gênero, conseqüência, entre outros fatores, das facilitações do acesso à produção pela via digital, o documentário hoje promove atração que abarca várias faces do campo da comunicação não podendo mais ser visto como circunscrito à especificidade da sua realização. Há, evidente, a mediação da câmera e as implicações éticas desta presença (Ramos, 2006) -, que remetem, em imediato, ao realizador que se descola, neste momento, das enumerações que rondam, ainda, a definição do documentário: 
representação fiel de personagens, de fatos ou revisão intencionalmente subjetiva do conteúdo registrado ou selecionado?

$\mathrm{Na}$ construção desta identidade não há unanimidade nem mesmo entre os cineastas que abraçam o gênero. Em uma discussão que reuniu Geraldo Sarno, Fernando Solanas e Evaldo Mokarzel, no programa "Cinema e Pensamento" do Canal Brasil, o primeiro classificou o documentário como "testemunho precário de um eu que se relaciona com o mundo" enquanto para o segundo, Fernando Solanas, as questões que envolvem a tensão entre ser objetivo ou subjetivo, não são exatamente um problema pois "O movimento social, as tensões políticosociais revigoraram o olhar objetivo do documentário". Já para Mokarzel, jornalista de formação, os documentários incorporam a sugestão de "realidade" e, portanto, é preciso que os documentaristas assumam o compromisso ético de serem fiéis ao que focam suas câmeras.

Voltamos aqui, portanto, ao que ainda parece ser uma definição impossivel de ser deslocada da interrogação do que é documentário: o seu vínculo com o mundo "real". E este vínculo é tanto mais cobrado quando o filme se insere em uma tradição que fez da produção documentarista atuação politica, instrumento de transformação, denúncia de injustiças sociais, como já destacado anteriormente. No entanto, justamente por estar embutido nesta "tradição" que se assume claramente militante e adepta de uma determinada visão de mundo ou ideologia, a presunção da "verdade" é a que mais lhe poderia escapar ao mesmo tempo que lhe confere maior "autenticidade" nos círculos que comungam este mesmo olhar do realizador. Para esta questão, Amado coloca:

"A relação entre a fiç̧ão e a verdade não deixa de ser problemática. Não menos que a que liga a verde e o gênero documental. A poética do cinema clássico, por exemplo - poética de ações e representações -,constrói intrigas nas quais o valor da verdade se sustenta com um sistema de arranjos e verossimilhanças que constitui o específico da ficção. No cinema documental, ao contrário, os fatos e ações são verdadeiros porque existentes e não imaginados, mas também submetidos a arranjos e jogos de verossimilhanças que, ao menos, comovem no seu afã de autenticidade e evidência". (Amado, 2005: 226). 
Amado está particularmente, neste artigo, discutindo o cinema militante de Michael Moore. Um cinema de onipresença do diretor, construída centralmente em torno da sua atuação, do seu percurso, da sua relação direta com os fatos e presenças escolhidas para serem o "tema" da sua obra. Neste embate, a reação dos entrevistados que o diretor localiza como "do lado de lá" da causa que abraçou - alguns, em fuga; outros, mudos diante da câmera e outros, ainda, com um discurso formal, que nada responde - é parte fundamental da dramatização construída para que o espectador "veja", "confira", "perceba" o que antes estava ocultado. São peças de convicção, com as intervenções diretas do diretor.

Solanas trabalha em outra clivagem (apesar do recurso, idem, do testemunho-presença do diretor sem, claro, a atuação dramatizada e ostensiva de Moore), quando recupera as tradições do gênero e não se furta a construir um enunciado que é consistente por apresentar dados, constatar conseqüências mas, também, por não se negar a "interpretar" as situações, recuperando, tanto por imagens de arquivo quanto por processos de manipulação técnica da imagem e som - no sentido de configurar um outro sentido, em especial através de "estouro" dos pontos, do uso contrastante das cores, da composiçã̃o minuciosa do plano, da recorrência planejada da música e dos sons incidentais o que Grierson chama de "trabalhar criativamente a realidade" (Winston, 2005). Por isso mesmo, é possível concordar com o diretor argentino que reconhece na sua obra não exatamente um projeto que lhe configure o status de documentário e sim a explica como continuidade de um projeto que se define como "filme-ensaio": "La composición de un film, como de cualquier obra artística, no es un solo acto, sino un proceso que no es ni ordenado ni claro. El proceso creativo es siempre caprichoso, desordenado y caótico. El oficio no es otra cosa que ordenar la inspiración y el caos".(Solanas, site oficial do autor).

É claro que a obra não fica presa às intenções do autor. No entanto, é inegável que a coerência do propósito do autor, quando a pretensão é "documentar" a realidade, infere um percurso que se revela na obra, como conquistado ou não. Obra que pode ser inconclusa, pode provocar discordâncias, pode causar questionamentos quanto às "verdades" que ali apresenta e tantas outras reações que não cabe aqui ficar enumerando. O que salta, de qualquer forma, em "Memorias del 
saque", é a construção de um filme em que está presente o repertório do diretor com resultado que ultrapassa a denúncia, a provocação, o panfleto e se apresenta como um filme poético, com múltiplas camadas, que inquieta e, principalmente, deixa claro seus sentidos.

\section{Referências Bibliográficas}

AMADO, A. Michael Moore e uma narrativa do mal. In MOURÃO, M. D. e LABAKI, A. (orgs). O Cinema do Real. São Paulo: Cosac Naif, 2005.

CARROLL, N. Ficção, não-ficção e o cinema de asserção pressuposta: uma análise conceitual". In RAMOS, F. P. (org). Teoria Contemporânea do Cinema, vol. II. São Paulo: Senac, 2004.

BERNARDET, J-C. O autor no cinema. São Paulo: Edusp/ Brasiliense, 1994.

DA-RIN, S. Espelho Partido. Tradição e transformação do documentário. Rio de Janeiro: Azougue editorial, 2004.

GETINO, O. Cine argentino - entre lo posible y lo deseable. $2^{a}$ ed. Buenos Aires: Ediciones Ciccus/INCAA, 2005.

LABAKI, A e CEREGHINO, M. J. Solanas por Solanas. São Paulo: Iluminuras/Memorial, 1993.

NICHOLS, B. Introdução ao Documentário. Campinas: Papirus, 2005. . A voz do documentário in RAMOS, F. P. (org). Teoria Contemporânea do Cinema, vol. II. São Paulo: Senac, 2004. PARANAGUÁ, P. Cinema na América Latina - Longe de Deus e perto de Hollywood. Porto Alegre: L\&PM, 1984.

RAMOS, F. P. A cicatriz da tomada: documentário, ética e imagem-intensa. In RAMOS, F. P. (org). Teoria Contemporânea do Cinema", vol. II. São Paulo: Senac, 2004.

WINSTON, B.. A maldição do 'jornalístico'na era digital. In MOURÃO, M. D. e LABAKI, A. (orgs). O Cinema do Real. São Paulo: Cosac Naif, 2005.

\section{Notas}

${ }^{2} \mathrm{O}$ exilio na França rendeu a Solanas, além do documentário feito sob encomenda "La mirada de los otros" (o que não o impediu de 
realizar uma obra muito pessoal) o comemorado "Tangos, o exílio de Gardel". Concluído em 1985, dois anos após sua volta à Argentina, "Tangos" nasce, também, da relação intensa que Fernando Solanas tem com a música e com uma estratégia narrativa visceralmente pautada pela história do seu país e pelo período em que foi obrigado a viver fora da Argentina. A lógica do filme tem como premissa as situações opostas que os exilados, naquele momento, viveram em relação à história do mítico cantor de tangos. Este, francês, foi parar na Argentina, enquanto o inverso aconteceu com um grupo de argentinos, entre eles, claro, Solanas. Assim, apesar de inscrito no campo ficcional, tanto quanto seu filme posterior, "Sur" - também referente ao exílio só que um exílio na própria Argentina, já que no país as identidades explícitas deveriam estar em sintonia com as determinações da ditadura, sob risco de prisão, seqüestro e morte - “Tangos" está radicalmente imbricado à trajetória do seu diretor. 